\title{
Experimental Test Bench for Performance-Assessment of Large Submersible and Dry-Action Pumps Used in Waterways
}

\author{
Joris HARDY ${ }^{1, \bigotimes}$, Pierre DEWALLEF ${ }^{1}$, Sébastien ERPICUM ${ }^{1}$, Michel PIROTTON ${ }^{1}$, \\ Darren PARKINSON ${ }^{2}$, Nigel TAYLOR ${ }^{2}$, Chris BARNET ${ }^{2}$, Paula TREACY ${ }^{3}$, \\ Olivier THOMÉ ${ }^{1}$, Pierre ARCHAMBEAU ${ }^{1}$, and Benjamin DEWALS ${ }^{1}$ \\ ${ }^{1}$ Université de Liège, School of Engineering, Liège, Belgium \\ ${ }^{2}$ Canal \& River Trust (CRT), United Kingdom \\ ${ }^{3}$ Waterways Ireland (WI), Ireland \\ $\bowtie$ joris.hardy@uliege.be
}

\begin{abstract}
Pumping in waterways, particularly in artificial canals, is energy-intensive, costly and may be responsible for the emission of large quantities of $\mathrm{CO}_{2}$. Innovative pumping technologies have the potential to reduce energy consumption; but their performance needs to be thoroughly assessed. This communication presents the design, sizing and construction of an experimental test bench for evaluating the performance of large submersible and dry-action centrifugal pumps typically used in waterways. It enables testing prototype-scale pumps and was designed in close collaboration with stakeholders such as canal operators. This experimental facility is challenging on many aspects given its size, as well as requirements for power supply and for measurement of system efficiency.
\end{abstract}

Keywords: experimental test bench, waterways, pumps, stainless steel pipe design, flow instrumentation.

\section{DESIGN AND SIZING}

The overall objective of the test bench is to enable monitoring the efficiency of submersible and dry-action centrifugal pumps under a broad range of operating conditions. The primary goal 
being the assessment of pumps typically used for lifting water in artificial waterways, the capacity requirements for the test bench were defined in close collaboration with stakeholders, mostly canal operators. This lead to the following specifications: pressure up to 10 bars, flow rate up to $0.3 \mathrm{~m}^{3} / \mathrm{s}$, power supply up to $300 \mathrm{~kW}$ and pumps of up to 2 tons in weight (Table 1). Given these specifications, various aspects of the test bench were designed and sized: layout of stainless steel pipes, pipe diameters, water supply system, regulating valve, energy dissipation system, power electronic boxes with safety and emergency systems, pressure measurement devices and release of entrapped air, among others. A closed-loop system was selected. The overall layout is represented in the CAD model shown in Fig. 1. The positioning of dry-action pumps to be tested is sketched on the right side of the figure, while submersible pumps to be tested shall be installed inside the large tank (visible on the left of the figure).

Table 1

Main characteristics of the test bench

\begin{tabular}{|l|c|l|c|l|c|}
\hline \multicolumn{2}{|c|}{ Tank characteristics } & \multicolumn{2}{c|}{ Pump characteristics } & \multicolumn{2}{c|}{ Test bench characteristics } \\
\hline Weight & $3.5 \mathrm{~T}$ & Weight max & $2 \mathrm{~T}$ & Sensors & $10+$ \\
\hline Capacity & $30 \mathrm{~m}^{3}$ & Power max. & $300 \mathrm{~kW}$ & Area & $8 \mathrm{~m} \times 10 \mathrm{~m}$ \\
\hline Diameter & $3 \mathrm{~m}$ & Flow rate max. & $300 \mathrm{l} / \mathrm{s}$ & Piping weight & $2 \mathrm{~T}$ \\
\hline Height & $4.5 \mathrm{~m}$ & Pressure max. & $10 \mathrm{bar}$ & Height max. & $4.5 \mathrm{~m}$ \\
\hline
\end{tabular}

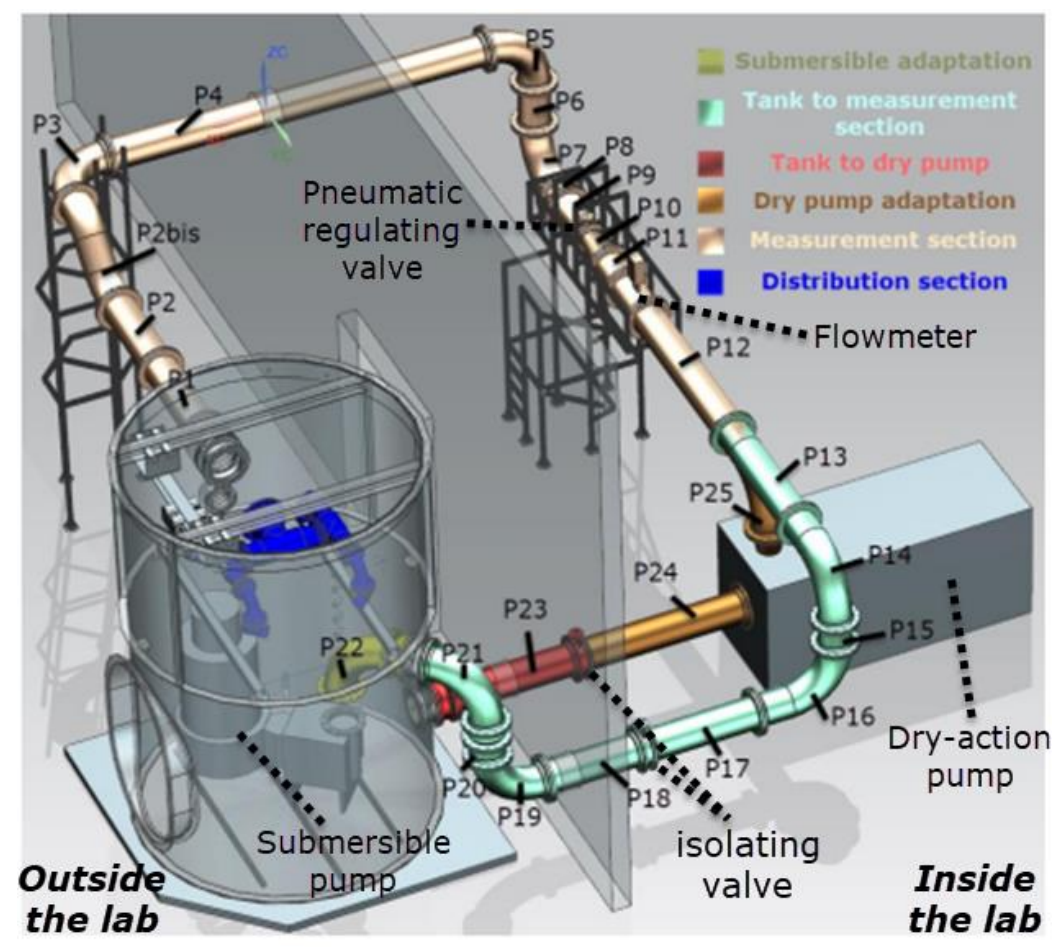

Fig. 1. Layout of the test bench.

The measurement system includes a flowmeter, a regulating valve (to adjust the head), pressure transducers as well as a power analyser and NI data logger. The main pipes have a diameter DN350, allowing friction losses to remain relatively low and ensuring that the diameter of the pump outlet is smaller than the pipe diameter. Sufficiently long straight pipe sections are placed 
at the inlet of the flowmeter as well as for the suction pipe of dry-action pumps, to ensure uniform velocity distribution and equalised pressure on the considered section as this helps avoiding swirl conditions.

The diameter and the height of the main tank were determined to prevent swirl conditions at the inlet of the submersible pumps (Sulzer-Pumpen 2010). Given the resulting dimensions ( $3 \mathrm{~m}$ in diameter and $4.5 \mathrm{~m}$ in height), the main tank was not available off-the-shelf; but it was manufactured on purpose for the test bench. It is made of stainless steel and its sizing accounts for a variety of constrains, including mechanical strength (finite element simulations were performed to size the curved door and lid), manufacturing process, pump installation procedure and test operations. The door is curved to withstand the inside pressure when the tank is filled with water. The stainless steel sheets are all minimum $6 \mathrm{~mm}$ thick. An energy dissipation system, made of several distribution pipes (in dark blue in Fig. 1), is installed at the inlet of the tank to further contribute to avoiding swirl conditions close to the inlet of submersible pumps. A regulating valve is used to adjust the head losses in the hydraulic loop by varying the valve opening angle (between $30^{\circ}$ and $70^{\circ}$ ). Given the specifications on the operation range of the pumps to be tested, a butterfly valve of diameter DN200 was selected.

\section{OPERATION}

Once a pump is installed, the operating procedure is the same for both submersible and dryaction pumps. The regulating valve and the rotation speed of the pump are electronically steered to browse a range of operating points. The pump is started at its nominal rotating speed, with the lowest opening angle of the regulating valve $\left(30^{\circ}\right)$. While the measurements in the bench are continuously recorded at a high frequency, the opening angle is increased by steps of $10^{\circ}$, up to the maximum flow rate of the pump or the valve maximum opening angle is reached. Then, the operation is repeated in reversed order, by decreasing the valve opening angle by steps of $10^{\circ}$. Next, the pump rotating speed is decreased by a predefined step and the whole operation is repeated again. This enables characterizing steady operating points of the pump for a representative range of heads and rotational several speeds. The characteristic curve of the pump can be redrawn with associated performance for nominal and non-nominal operation. Submersible pumps to be tested are placed inside the tank through the door using a fork truck lift machine and the bridge crane installed at the top of the tank while dry-action pumps are placed inside laboratory.

Acknowledgments. This research is partly supported by ERDF funding in the framework of the Interreg NWE project Green WIN. CRT and WI are gratefully acknowledged.

\section{References}

Sulzer-Pumpen (2010), Special data for planning centrifugal pump installations. In: Sulzer-Pumpen (eds.), Centrifugal Pump Handbook, 3rd ed., Elsevier Science, 91-97.

Received 22 March 2021

Accepted 12 April 2021 